\title{
Hysterectomy or a minimal invasive alternative? A systematic review on quality of life and satisfaction
}

\author{
H. A. M. Brölmann • A. J. BijdeVaate • \\ A. Vonk Noordegraaf • P. F. Janssen • J. A. F. Huirne
}

Received: 20 March 2010 / Accepted: 26 April 2010 / Published online: 22 May 2010

(C) The Author(s) 2010. This article is published with open access at Springerlink.com

\begin{abstract}
Nowadays, an increasing number of minimal invasive treatment alternatives to hysterectomy may be offered to the patient. In determining the appropriate treatment option, the patient has a distinct dilemma if a minimal invasive treatment with lesser effect than hysterectomy should be chosen or if a hysterectomy should be chosen which is a major surgery and requires longer recovery than the minimal invasive alternative. Quality-oflife (QoL) questionnaires that take subjective health perception into account are currently used to assess the treatment effects. The objective of this literature study is to determine and discuss the role of QoL as an outcome in randomized controlled trials (RCT) or systematic reviews of RCTs that study the treatment effect of hysterectomy compared to that of minimal invasive alternatives. A systematic literature search was performed in the PubMed database and in the Cochrane database to find randomized trials and systematic reviews of randomized trials, comparing hysterectomy with minimal invasive or conservative treatment options with sufficient follow-up using satisfac-
\end{abstract}

Declaration of interest The authors report no conflicts of interest. The authors alone are responsible for the content and writing of the paper.

H. A. M. Brölmann $(\bowtie) \cdot J$. A. F. Huirne

Department of Gynecology, VU University Medical Center,

De Boelelaan 1117,

1181HV Amsterdam, the Netherlands

e-mail: h.brolmann@vumc.nl

A. J. BijdeVaate $\cdot$ P. F. Janssen

Resident Obstetrics and Gynecology, VU University center,

Amsterdam, the Netherlands

A. Vonk Noordegraaf

Research Fellow Obstetrics and Gynecology, University Center,

Amsterdam, the Netherlands tion, health status, and quality of life as outcomes. The results were based on nine randomized trials and two systematic reviews. The differences are mostly in favor of hysterectomy. In two out of four studied treatment alternatives, the satisfaction or health status is different in favor of hysterectomy while the QoL is equivalent. After 2 years of follow-up, differences between both groups have disappeared, possibly because of the crossover effect. Possible reasons for the lesser response of QoL compared to satisfaction or health status are discussed. The fundamental question if patients have a better quality of life at all times if they choose for a minimal invasive alternative of hysterectomy remains unresolved. Information, individualization, and freedom of choice before surgery probably best serve the sense of well being and quality of life thereafter.

Keywords Hysterectomy - Medical treatment - Endometrial ablation - Embolization - Mirena - Quality of life .

Satisfaction $\cdot$ Randomized controlled trial

\section{Background}

Despite an increasing number of alternative minimal invasive treatment options, the hysterectomy in the Netherlands is still frequently performed in premenopausal patients with uterine symptoms. According to a Dutch hospital-based database (Prismant), approximately 16,000 hysterectomies are performed each year. Alternative treatment options are medical treatment, including the levonorgestrel-delivering intrauterine system (LNG-IUS), endometrial ablation, embolization or occlusion of uterine vessels, and the partial removal of uterine structures such as polyps, fibroids, and the uterine corpus (subtotal hysterectomy). 
The dilemma for patients and doctors in the choice between hysterectomy and minimal invasive or conservative treatment is the tradeoff between a faster recovery in minimal invasive surgery and the possibly lesser effect of the treatment.

There have been different ways in evaluating treatment, such as satisfaction and health status (e.g., symptom score). In 1952, WHO reformulated the definition of health being "not only the absence of disease or infirmity, but also the presence of physical, mental and social wellbeing," hereby introducing a subjective element in the definition of health [1]. The - subjective - perception of health determines the quality of life (QoL). Instead of using outcomes such as satisfaction of treatment or health status, the treatment effect is increasingly measured as QoL. QoL is measured ideally by questionnaires that have been validated to be reliable, reproducible, and specific [2]. In generic QoL questionnaires, the general health is inquired, while in diseasespecific QoL, the questions apply more to specific medical situations. The latter questionnaires are more appropriate to assess treatment effects. QoL should be distinguished from health status (e.g., menstrual score) or satisfaction after treatment, which are considered causal items where the QoL is based upon. Although QoL seems an appropriate outcome to compare conventional and minimal invasive treatment, the results sometimes differ from the health status or the level of satisfaction. It is therefore a matter of debate on what results patients should be counseled.

The objective of this literature study is to determine and discuss the role of QoL as an outcome in randomized controlled trials (RCT) or systematic reviews of RCTs that study the treatment effect of hysterectomy compared to that of minimal invasive alternatives.

\section{Method}

A systematic literature search was performed in the PubMed database and in the Cochrane database to find systematic reviews of randomized trials, comparing hysterectomy with minimal invasive or conservative treatment options [medical treatment including LNG-IUS, endometrial ablation, and uterine artery embolization (UAE) or ligation] with sufficient follow-up using satisfaction, health status, and quality of life as outcomes. If no systematic reviews or later published data were available, then randomized trials were also included. The search terms ("menorrhagia" [Mesh] OR "leiomyoma" [Mesh] AND "Quality of Life" [Mesh] AND "Hysterectomy" [Mesh]) limited to randomized trials or reviews were used in the PubMed database as well as in the Cochrane database.

From the PubMed database, 26 articles meeting the search terms were found, of which two were Cochrane systematic reviews $[3,4]$. There were four randomized trials detected that met the criteria [5-8]. Two articles on first-generation endometrial ablation $[9,10]$ met the criteria but were appropriately reported in the identified systematic review. Checking cross references from this review, four more randomized trials were identified [11-14]. From the Cochrane database using the Mesh terms "hysterectomy" and "Quality of life," two hits with regard to systematic reviews were retrieved and 43 trials. The two systematic reviews were already found in the PubMed database. Three more potentially suitable trials were found but were excluded [15-17]. In one study that compared uterine artery ligation with hysterectomy, only the design was described [17]. Follow-up lacked in another study [15], and quality of life was not used as an outcome in the third excluded study [16]. With the mesh term "uterine artery embolization," one more Cochrane review was detected [18]. However, this review addressed short-term results, and no follow-up was reported, while later published articles reported follow-up data on uterine artery embolization [6,7]. The process of selection was done by two authors (JH, HB) independently. No cases of disagreement occurred.

On four minimal invasive or conservative therapies, we found systematic reviews or RCTs comparing them with hysterectomy. These alternative treatment options were hormonal medication [4, 5], LNG-IUS (Mirena) [4, 8], first-generation endometrial ablation $[3,10]$, and UAE [6, 7]. On the other minimal invasive treatment options (myomectomy, occlusion of the uterine artery), no randomized trials could be found in the aforementioned databases and the international trial register (http://clinicaltrials.gov/ ct $2 /$ search/browse?brwse $=$ cond_cat_BXS).

\section{Findings}

The randomized trials on which the reviews were based on are presented in Table 1. Conclusions of these reviews and articles are briefly reported below according to satisfaction, health status, and quality of life.

\section{Medical treatment}

In the Cochrane review of Marjoribanks et al. [4], studies were systematically collected that compared medical treatment with surgery, including hysterectomy in premenopausal women with heavy menstrual bleeding. Eight studies met the inclusion criteria. The authors randomized a total of 821 women, 411 receiving surgery and 410 receiving medical treatment.

The authors conclude in the abstract: "surgery, especially hysterectomy, reduces menstrual bleeding at one year more 
Table 1 Randomized controlled trials comparing conservative or minimal invasive surgery with hysterectomy

\begin{tabular}{|c|c|c|c|c|c|c|}
\hline Author & Year & $\begin{array}{l}\text { Number of } \\
\text { patients }\end{array}$ & Control treatment & QoL questionnaire & $\begin{array}{l}\text { Health status } \\
\text { instrument }\end{array}$ & Follow-up \\
\hline Kupperman [5] & 2004 & 63 & Oral medical & SF-36 & Satisfaction & 6 months, 2 years, 5 years \\
\hline Hurskainen $[8,15]$ & 2001,2004 & 236 & LNG-IUS & SF-36, EQ5 & Satisfaction & 1 year, 5 years \\
\hline Crosignani [9] & 1997 & 85 & $\mathrm{TCRE}^{\mathrm{a}}$ & SF-36 & Satisfaction & 2 years \\
\hline Dwyer [12] & 1993 & 196 & TCRE & SF-36 & Satisfaction & 2,8 years \\
\hline Gannon [13] & 1991 & 51 & TCRE & - & Satisfaction & 1 year \\
\hline O'Connor [14] & 1997 & 172 & TCRE & General health & Satisfaction & 2 years \\
\hline Pinion [11] & 1994 & 202 & TCRE & $\begin{array}{l}\text { Psychosocial adjustment } \\
\text { to illness }\end{array}$ & Satisfaction & 4 years \\
\hline Hehenkamp [6] & 2008 & 177 & $\begin{array}{l}\text { Uterine artery } \\
\text { embolization }\end{array}$ & SF-36, EQ5 & Satisfaction & 2 years \\
\hline Edwards & 2007 & 51 & $\begin{array}{l}\text { Uterine artery } \\
\text { embolization }\end{array}$ & SF 36 & $\begin{array}{l}\text { Symptom } \\
\text { score }\end{array}$ & 1 year \\
\hline
\end{tabular}

TCRE transcervical resection of the endometrium

than medical treatments but LNG-IUS appears equally effective in improving quality of life. The evidence for longer term comparisons is weak and inconsistent. Oral medication suits a minority of women long term."

We will address the comparison of hysterectomy and LNG-IUS separately in the next section.

In one study, hysterectomy was the intervention which was compared with oral medical treatment [5], and validated quality-of-life questionnaires were used. In this study of Kuppermann et al. [5], 63 premenopausal patients with abnormal uterine bleeding and dissatisfied with medical treatments, including medroxyprogesterone, were randomized to continuation of that medical treatment or hysterectomy. The outcomes were two summary indexes of the short form (SF)-36. The primary outcome was the mental component score; secondary outcomes were the physical component score, symptom relief, and satisfaction. In an intention-to-treat analysis, only a weak difference of the mental component score of the SF-36 between the groups was demonstrated after 6 months, while the difference in satisfaction was more pronounced in favor of hysterectomy (Table 2). After 2 years, no differences between groups were found in the SF-36 and satisfaction.
At that time, $33 / 63(53 \%)$ of patients of the medical treatment arm had "crossed over" to hysterectomy.

\section{LNG-IUS}

The part of the systematic review of Marjoribanks [4] addressing hysterectomy versus LNG-IUS was based on the randomized trial of Hurskainen et al. [8, 19]. In this trial, 107 patients with heavy menstrual bleeding were treated with hysterectomy and 118 with the LNG-IUS. Two articles after 1 and 5 years reported the health-related quality of life (HRQL) to be equal between both treatment arms based on an intention-to-treat analysis (Table 3). After 5 years of follow-up, general health status as measured by visual analog scale was significantly improved in the hysterectomy group $(p=0.04)$, but not in the LNG-IUS group ( $p=$ 0.08 ), with no substantial difference between groups. Satisfaction was assessed by a five-level question and did not differ between treatment arms. These data are not shown in the results section, but only mentioned in the abstract. Therefore, it is not possible to assess the level of satisfaction in both groups. After 5 years, a hysterectomy was performed in $42 \%$ of the LNG-IUS patients. In this

Table 2 Differences between treatment arms in mental component score of the SF-36 and the physical component score of the SF-36

\begin{tabular}{lccc}
\hline & \multicolumn{2}{c}{ Difference between medical treatment and hysterectomy arm (+ in favor of hysterectomy) } \\
\cline { 2 - 4 } SF-36 & Follow-up 6months & $p$ & Follow-up 2years \\
\hline Mental component summary & $+6($ CI $0.4-12)$ & 0.04 & $+3($ CI $-2-7)$ \\
Physical component summary & $+3($ CI $-2-8)$ & 0.21 & $-2(-5-1)$ \\
Symptom resolution (\%) & $46(29-63)$ & $<0.001$ & 0.25 \\
Satisfaction with symptom level & $37(21-52)$ & $<0.001$ & $6(-2-31)$ \\
\hline
\end{tabular}

Randomized between continuation of medication and hysterectomy were 236 premenopausal patients with abnormal uterine bleeding [5] 
Table 3 Treatment effect (difference between groups) in EQ5 score in 232 patients after LNG-IUS and hysterectomy after 1 and 5 years

\begin{tabular}{lcc}
\hline EQ5 dimensions & Difference in EQ5 score & Confidence interval \\
\hline Follow-up 1 year & 0.0 & $-0.05-0.05$ \\
Follow-up 5 years & 0.02 & $-0.05-0.009$ \\
\hline
\end{tabular}

subgroup, the HRQL was significantly lower than in the group who had the LNG-IUS after 5 years in situ.

In the conclusion, the authors state that "the LNG-IUS may improve HRQL at relatively low cost, undoubtedly enhances patient choice, and may reduce surgery-related costs."

First-generation ablation

In the Cochrane review of Lethaby et al. [3], five RCTs of endometrial destruction versus hysterectomy with a total of 752 participants met the criteria and were included. Patients were analyzed according to the intention-to-treat analysis, and a significant difference of the satisfaction rate was found in favor of the hysterectomy after 1 and 2 years. See Table 4. After 3 and 4 years, the differences lost its statistical significance.

Although many quality-of-life scales reported no differences between surgery groups, there was some evidence of a greater improvement in general health for hysterectomy patients after 1 and 2 years, when compared to those who had endometrial destruction. This was also the case after 2 years of follow-up in the SF-36 domains social functioning and pain. After 4 years, this difference between groups had narrowed and was just outside the 0.05 level of significance.

Reintervention rate in patients treated by ablation ranged from $14 \%$ after 1 year to $38 \%$ (only hysterectomies) after 4 years.

The authors conclude that "endometrial destruction is an alternative to hysterectomy that should be offered to women with heavy menstrual bleeding. There are high satisfaction rates, shorter operation time and hospital stay, earlier recovery and reduced post-operative complications." They stress however that the patient should be informed

Table 4 Treatment effect with regard to satisfaction rate and quality of life comparing endometrial ablation and hysterectomy in a systematic review

\begin{tabular}{lccc}
\hline Patient satisfaction & $N$ studies & $N$ patients & Effect size $(95 \% \mathrm{CI})$ \\
\hline 1 year & 3 & 529 & $0.46(0.24-0.88)$ \\
2 years & 3 & 354 & $0.31(0.16-0.59)$ \\
3 years & 1 & 82 & $0.32(0.08-1.37)$ \\
4 years & 1 & 148 & $0.52(0.21-1.26)$ \\
\hline
\end{tabular}

Statistics with Pete odds ratio [3] about the higher risk of reoperation after endometrial destruction.

Uterine artery embolization

In two randomized trials, the UAE is compared to hysterectomy in terms of satisfaction and quality of life. In the EMMY trial [6], more than $90 \%$ of patients in both groups were at least moderately satisfied after a follow-up of two years, but a larger proportion of the patients in the hysterectomy group was satisfied to very satisfied $(45 / 75=$ $60 \%)$ compared with the UAE group $(34 / 81=42 \% ; p=$ 0.026). However, the primary outcome, the quality of life measured by generic (SF36 and EQ5) as well as healthrelated questionnaires, did not differ after 2 years. The "crossover" to hysterectomy in the UAE group was $25 \%$. In the conclusion of the abstract, it is stated that "on the basis of HRQOL results, the authors determined that UAE is a good alternative to hysterectomy." In the second study of Edwards et al. [7], patients undergoing UAE $(n=106)$ were compared to patients undergoing surgery (43 hysterectomies and eight myomectomies). After 1 year of follow-up, no differences of the eight components of the SF-36 scores were found between both groups, while the symptom scores were better in the surgical group $(p=0.03)$. In the UAE group, 21 patients $(20 \%)$ required within 1 year a reintervention, such as hysterectomy or repeated embolization for inadequate symptom control. The authors conclude in the abstract that "In women with symptomatic fibroids, the faster recovery after embolization must be weighed against the need for further treatment in a minority of patients."

\section{Discussion}

While in the past the hysterectomy was the treatment of choice in case of benign gynecological disorders, nowadays, many alternative treatment options are available that are less invasive and preserve the uterus. In the office, the challenge is to support patients in their dilemma of choosing hysterectomy with adequate symptom relief or minimal invasive treatment with a risk of lesser symptom control.

In this systematic literature review, articles are addressed that study in a randomized way the comparison of hysterectomy and a conservative or lesser invasive alternative, such as 
Table 5 Semiquantitative ranking based on statistical significance of treatment effect (difference between treatment arms) in terms of symptom relief (satisfaction) and quality of life $(++,+, \pm,-)$

\section{Difference between treatment arms in favor of hysterectomy}

Treatment compared with hysterectomy

Relief of symptoms (satisfaction) Quality of life

$$
++,+, \pm,-\quad p \text { value or } \mathrm{CI} \quad++,+, \pm,-\quad p \text { value }
$$

\begin{tabular}{llllll}
\hline Medical treatment [5] & ++ & $<0.001$ & + & 0.04 & 53 \\
LNG-IUS (Mirena) [8] & - & Not stated & - & 0.60 & 42 \\
Endometrial ablation (1st generation) $[9]^{\mathrm{c}}$ & + & Significant & \pm & NS & 38 \\
Uterine artery embolization [6] & + & 0.04 & - & 0.62 & 25
\end{tabular}

${ }^{\text {a After }} 6$ months of follow-up. QoL SF-36 mental component score, satisfaction symptom list of SF-36 physical component score

${ }^{\mathrm{b}}$ With the Euroqol 5 after 2 years of follow-up. Satisfaction was only mentioned in the abstract.

${ }^{\mathrm{c}}$ After 2 years of follow-up, the Euroqol 5 showed no difference between groups; however, general health perception in the SF-36 did

${ }^{\mathrm{d}}$ After 2 years of follow-up. The $p$ value is of the Euroqol 5 QoL questionnaire. No other QoL instruments showed a significant difference between groups.

medical treatment, endometrial ablation, and uterine artery embolization. In general, the differences in satisfaction of treatment or in health status between treatment arms are more prominent in terms of statistical significance than the differences of QoL. The difference is mostly in favor of hysterectomy which is presented in Table 5. In two out of four studied treatment alternatives, the satisfaction or health status is different in favor of hysterectomy while the QoL is equivalent in both treatment arms. After 2 years of followup, differences between both groups have disappeared, possibly because of the crossover effect.

How can it be explained that this response of treatment satisfaction is better than the response of QoL and what consequence may it have for our recommendations to the patient? Two suppositions may explain that quality of life is less or not at all responsive after treatment. First, we can assume that there is a difference in quality of life which is not detected. The second explanation is that, despite differences in symptom control between treatment arms, the patients experience indeed no differences in quality of life.

Let us first elaborate on the possibility that there is a difference in quality of life between hysterectomy and the minimal invasive alternative which is not detected. In all studies that report a difference in QoL that is not statistically significant, this difference is in favor of the hysterectomy. Therefore, insufficient power may play a role, although in other studies with comparable numbers comparing gynecological surgery, significant treatment effects have been demonstrated by QoL questionnaires (SF-36) [20].

In all trials, generic QoL questionnaires were used, such as the SF-36, the Euroqol five (EQ5) dimensions, and the Nottingham health profile. It is well established that disease-specific questionnaires are more responsive to treatment effects than generic questionnaires that are designed to measure health-related quality of life across a wide variety of diseases [21]. Nowadays, validated instru- ments are available that measure QoL in benign gynecological disease, such as the uterine fibroid symptom list designed by Spies et al. [22]. Also, for menorrhagia, various lists are reported in the literature [23]. It is recommended for optimal sensitivity and responsiveness in clinical trials to use a combination of a generic and a disease-specific questionnaire [24].

The second possibility is that there is no difference in QoL between groups indeed despite a significantly differing symptom control between treatment arms. This could be explained by the fact that patients undergoing a minimal invasive treatment take a lesser effect into account. Consequently, they are not unhappy in all cases if the treatment has failed. It is well known from preference trials that the majority of women are willing to accept a failure rate of the minimal invasive option up to $50 \%$ in escaping a hysterectomy [25].

In the reported studies, a large proportion of patients randomized to the minimal invasive alternative treatment eventually "crossed over" to hysterectomy (25-53\%). Intention-to-treat analysis may equalize effects and explain the disappearance of the differences over time. This accounts for quality of life and to a lesser extent for health status (satisfaction) as the difference in health status is larger from the start. In the study of Hehenkamp et al. [6], after 2 years of follow-up, satisfaction differed significantly between treatment arms (UAE and hysterectomy) while no time effect and treatment effect of the quality of life were reported.

\section{Conclusion}

In conclusion, the fundamental question if patients have a better quality of life at all times if they choose for a minimal invasive alternative of hysterectomy remains 
unresolved. Some do and some do not. As quality of life depends on the extent to which patients' expectations are matched by reality [26], adequate information beforehand on the surgical options, tailored to the particular situation of the patient, is of utmost importance. In this way, the individual preference of the patient can be best explored. If the patient is well prepared on certain risk of treatment failure, the eventual period of complaints and concerns to come to a decision of an often more invasive reintervention is better coped with and may not be reflected in the QoL. The QoL of patients crossing over has been reported significantly worse than in the group of patients that comply with their original treatment [8].

Information, individualization, and freedom of choice before surgery probably best serve the sense of well being and quality of life thereafter.

Open Access This article is distributed under the terms of the Creative Commons Attribution Noncommercial License which permits any noncommercial use, distribution, and reproduction in any medium, provided the original author(s) and source are credited.

\section{References}

1. Constitution of the World Health Organization (WHO) (1952) Handbook of basic documents. WHO, Geneva, pp 3-20

2. Testa MA (2000) Interpretation of quality-of-life outcomes: issues that affect magnitude and meaning. Med Care 38:II166-II174

3. Lethaby A, Shepperd S, Cooke I, Farquhar C (2000) Endometrial resection and ablation versus hysterectomy for heavy menstrual bleeding. Cochrane Database Syst Rev: CD000329

4. Marjoribanks J, Lethaby A, Farquhar C (2006) Surgery versus medical therapy for heavy menstrual bleeding. Cochrane Database Syst Rev; CD003855

5. Kuppermann M, Varner RE, Summitt RL Jr, Learman LA, Ireland C, Vittinghoff E, Stewart AL, Lin F, Richter HE, Showstack J, Hulley SB, Washington AE (2004) Effect of hysterectomy vs medical treatment on health-related quality of life and sexual functioning: the medicine or surgery (Ms) randomized trial. JAMA 291:1447-1455

6. Hehenkamp WJ, Volkers NA, Birnie E, Reekers JA, Ankum WM (2008) Symptomatic uterine fibroids: treatment with uterine artery embolization or hysterectomy-results from the randomized clinical Embolisation Versus Hysterectomy (EMMY) Trial. Radiology 246:823-832

7. Edwards RD, Moss JG, Lumsden MA, Wu O, Murray LS, Twaddle S, Murray GD (2007) Uterine-artery embolization versus surgery for symptomatic uterine fibroids. N Engl J Med 356:360-370

8. Hurskainen R, Teperi J, Rissanen P, Aalto AM, Grenman S, Kivela A, Kujansuu E, Vuorma S, Yliskoski M, Paavonen J (2004) Clinical outcomes and costs with the levonorgestrelreleasing intrauterine system or hysterectomy for treatment of menorrhagia: randomized trial 5-year follow-up. JAMA 291:1456-1463

9. Crosignani PG, Vercellini P, Apolone G, De Giorgi O, Cortesi I, Meschia M (1997) Endometrial resection versus vaginal hysterectomy for menorrhagia: long-term clinical and quality-of-life outcomes. Am J Obstet Gynecol 177:95-101
10. Sculpher MJ, Dwyer N, Byford S, Stirrat GM (1996) Randomised trial comparing hysterectomy and transcervical endometrial resection: effect on health related quality of life and costs two years after surgery. Br J Obstet Gynaecol 103:142-19

11. Pinion SB, Parkin DE, Abramovich DR, Naji A, Alexander DA, Russell IT, Kitchener HC (1994) Randomised trial of hysterectomy, endometrial laser ablation, and transcervical endometrial resection for dysfunctional uterine bleeding. BMJ 309:979-983

12. Dwyer N, Hutton J, Stirrat GM (1993) Randomised controlled trial comparing endometrial resection with abdominal hysterectomy for the surgical treatment of menorrhagia. $\mathrm{Br} \mathrm{J}$ Obstet Gynaecol 100:237-243

13. Gannon MJ, Holt EM, Fairbank J, Fitzgerald M, Milne MA, Crystal AM, Greenhalf JO (1991) A randomised trial comparing endometrial resection and abdominal hysterectomy for the treatment of menorrhagia. BMJ 303:1362-1364

14. O'Connor H, Broadbent JA, Magos AL, McPherson K (1997) Medical Research Council randomised trial of endometrial resection versus hysterectomy in management of menorrhagia. Lancet 349:897-901

15. Varner RE, Ireland CC, Summitt RL Jr, Richter HE, Learman LA, Vittinghoff E, Kuppermann M, Washington E, Hulley SB (2004) Medicine or surgery (Ms): a randomized clinical trial comparing hysterectomy and medical treatment in premenopausal women with abnormal uterine bleeding. Control Clin Trials 25:104-118

16. Learman LA, Summitt RL Jr, Varner RE, Richter HE, Lin F, Ireland CC, Kuppermann M, Vittinghoff E, Showstack J, Washington AE, Hulley SB (2004) Hysterectomy versus expanded medical treatment for abnormal uterine bleeding: clinical outcomes in the medicine or surgery trial. Obstet Gynecol 103:824-833

17. Kim HS, Kim JW, Kim MK, Chung HH, Lee TS, Jeon YT, Kim YB, Jeon HW, Yun YH, Park NH, Song YS, Kang SB (2009) A randomized prospective trial of the postoperative quality of life between laparoscopic uterine artery ligation and laparoscopyassisted vaginal hysterectomy for the treatment of symptomatic uterine fibroids: clinical trial design. Trials 10:8

18. Gupta JK, Sinha AS, Lumsden MA, Hickey M (2006) Uterine artery embolization for symptomatic uterine fibroids. Cochrane Database Syst Rev CD005073

19. Hurskainen R, Teperi J, Rissanen P, Aalto AM, Grenman S, Kivela A, Kujansuu E, Vuorma S, Yliskoski M, Paavonen J (2001) Quality of life and cost-effectiveness of levonorgestrelreleasing intrauterine system versus hysterectomy for treatment of menorrhagia: a randomised trial. Lancet 357:273-277

20. Cooper KG, Bain C, Lawrie L, Parkin DE (2005) A randomised comparison of microwave endometrial ablation with transcervical resection of the endometrium; follow up at a minimum of five years. BJOG 112:470-475

21. Jones GL, Kennedy SH, Jenkinson C (2002) Health-related quality of life measurement in women with common benign gynecologic conditions: a systematic review. Am J Obstet Gynecol 187:501-511

22. Spies JB, Coyne K, Guaou GN, Boyle D, Skyrnarz-Murphy K, Gonzalves SM (2002) The UFS-QOL, a new disease-specific symptom and health-related quality of life questionnaire for leiomyomata. Obstet Gynecol 99:290-300

23. Clark TJ, Khan KS, Foon R, Pattison H, Bryan S, Gupta JK (2002) Quality of life instruments in studies of menorrhagia: a systematic review. Eur J Obstet Gynecol Reprod Biol 104:96-104

24. Patrick DL, Bergner M (1990) Measurement of health status in the 1990s. Annu Rev Public Health 11:165-183

25. Bourdrez P, Bongers MY, Mol BW (2004) Treatment of dysfunctional uterine bleeding: patient preferences for endometrial ablation, a levonorgestrel-releasing intrauterine device, or hysterectomy. Fertil Steril 82:160-166, quiz

26. Calman KC (1984) Quality of life in cancer patients - an hypothesis. J Med Ethics 10:124-127 